\title{
EDITORIAL
}

\section{Understanding Lung Development, Injury, and Repair}

\author{
Chhavi Chauhan* and Kevin A. Roth
}

\begin{abstract}
From the American Society for Investigative Pathology, * Bethesda, Maryland (Scientific Editor); and the Department of Pathology and Cell Biology, ${ }^{\dagger}$ Columbia University Medical Center, New York, New York (Editor-in-Chief)
\end{abstract}

The three reviews in this special Lung Ontogeny and Injury Theme Issue of The American Journal of Pathology arose from a symposium at the 2015 American Society for Investigative Pathology Annual Meeting at Experimental Biology. This series provides critical insights into lung development, key pulmonary diseases like congenital diaphragmatic hernia, and lung injury and repair.

\section{Characterizing Lung Pericytes and Fibroblasts}

Barron et al $^{1}$ discuss the origin, characteristics, and pleiotropic roles of two distinct lung mesenchymal populations: pericytes and resident fibroblasts. They focus on exploring their roles during lung development, homeostasis, regeneration, and fibrotic disorders, as well as the use of fibroblasts as therapeutic targets.

\section{Exploring Congenital Diaphragmatic Hernia}

Donahoe et $\mathrm{al}^{2}$ shed light on our current understanding of the mechanisms of pulmonary defects in congenital diaphragmatic hernia, one of the most common and lethal congenital abnormalities. They begin by providing an overview of the diaphragm and lung development, followed by a discussion of the congenital diaphragmatic hernia-associated defects, and a comprehensive discussion of the various studied animal models with emphasis on the implicated molecular mechanisms. Last, they elaborate on the potential for targeting postnatal stages of lung development, for maximum clinical impact on the surviving cohorts.

\section{Pulmonary Stem Cells in Adult Lung Injury Repair}

Chen and Fine ${ }^{3}$ discuss the biology and phenotypes of endogenous lung stem and progenitor cells, their hierarchical relationships, their plasticity in adult lung injury repair, and the molecular mechanisms that regulate their differentiation. They discuss the currently available genetic models and further emphasize the importance of developing robust genetic tools to explore the underlying mechanisms during lung injury repair in adults. Finally, they draw attention to the challenges behind translating these findings to further understand pathogenesis and design treatments for human lung diseases.

\section{References}

1. Barron L, Gharib SA, Duffield JS: Lung pericytes and resident fibroblasts: busy multitaskers. Am J Pathol 2016, 186:2519-2531

2. Donahoe PK, Longoni M, High FA: Polygenic causes of congenital diaphragmatic hernia produce common lung pathologies. Am J Pathol 2016, 186:2532-2543

3. Chen F, Fine A: Stem cells in lung injury and repair. Am J Pathol 2016, 186:2544-2550

\footnotetext{
Accepted for publication August 8, 2016.

Disclosures: None declared.

K.A.R. compiled the Lung Ontogeny and Injury Theme Issue, which is based on the reviews from a symposium on Ontogeny and Injury in the Lungs at the 2015 American Society for Investigative Pathology Annual Meeting, held March 28-April 1, in Boston, MA.
}

Address correspondence to Kevin A. Roth, M.D., Ph.D., Department of Pathology and Cell Biology, Columbia University Medical Center, 630 W 168th St, PH15W-1564, New York, NY 10032. E-mail: karoth@ columbia.edu. 